\title{
The effect of interface morphology in waste tyre rubber powder filled elastomeric matrices on the tear and abrasion resistance
}

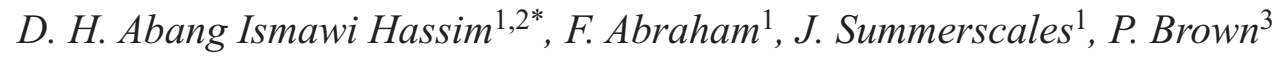 \\ ${ }^{1}$ School of Engineering, University of Plymouth, PL4 8AA Plymouth, United Kingdom \\ ${ }^{2}$ Malaysian Rubber Board, RRIM Experiment Station, 47000, Sg.Buloh, Selangor, Malaysia \\ ${ }^{3}$ Tun Abdul Razak Research Centre (TARRC), Malaysian Rubber Board, Brickendonbury, SG13 8 NL Hertford, \\ United Kingdom
}

Received 28 July 2018; accepted in revised form 15 October 2018

\begin{abstract}
The interface between either Micronised Rubber Powder (MRP) or Crumb Rubber Powder (CRP) fillers in either Natural Rubber (NR) or Butadiene Rubber (BR) matrices has been studied using Transmission Electron Microscopy (TEM) 'network visualisation'. The convoluted structure of CRP provides better interfacial adhesion than MRP. The weak interface between the MRP networks and the rubber matrix was confirmed by the lower physical bonding. The crescent tear strength test was able to characterise the possible weak interaction of MRP in unfilled NR or NR/BR blend matrix. The Akron test was used for carbon black-filled matrix.
\end{abstract}

Keywords: rubber, recycled rubber powder, tear strength, abrasion resistance, network visualisation

\section{Introduction}

Recycled rubber powders (RRP) from waste tyres, either as a treated or untreated filler are often incorporated into rubber formulations to provide economic and environmental benefits. High quality, smaller particle RRP used to replace virgin material could reduce the overall product carbon footprint. Less energy is consumed in the production and utilisation of recycled rubber products than from the virgin raw rubber material [1]. However, larger particle size, ambient ground RRP $(>400 \mu \mathrm{m})$ reduces the physical properties (tensile strength, elongation at break, abrasion resistance index, heat-build up, etc.) [2,3]. Cryogenic ground MRP has a smooth surface $[4,5]$ which restricts their potential and also leads to a decline in the physical properties [3]. Fine powders [6] $(<20 \mu \mathrm{m})$ improve the key properties and could provide many positive benefits in various engineering applications, relative to coarse particles. Smaller particles than $400 \mu \mathrm{m}$ for ambient ground RRP, currently only produced in small batches, are not readily commercially available with the only source being cryogenic ground production.

In a filled rubber, good matrix-filler bonding and a uniform filler network structure are essential for optimum reinforcement. The overall performance of the rubber/blend compound is governed by the strength of the filler-filler or rubber matrix-filler interfaces. Other factors such as distribution of filler, phase morphology, crosslinking system, and density are often studied to understand the properties of rubbers and their blends. Several techniques for measurement of rubber-filler interaction strength have been briefly described in the literature [7] including the dynamic mechanical method $[7,8]$. 
Cook and coworkers $[9,10]$ applied the network visualisation [11] technique to measure the crosslink density and qualitatively assess the interface strength between two different phases in rubber blends. This technique polymerises styrene monomer in the swollen rubber-filler matrix. The weak rubber-filler surface separates and becomes visible in TEM due to the formation of extended polystyrene regions called 'voids/ vacuoles' around the particles/interface.

This technique is also used in silica-filled rubber to analyse the morphology of filler to rubber interaction. Vacuoles were observed around silica particles without coupling agent as a result of a weak rubberfiller interaction [12, 13]. Martin et al. [14] used the same techniques to analyse rubber wear surfaces. In this research, TEM 'network visualisation' was carried out to investigate the interface morphology between RRP filler and either NR or BR matrix using similar techniques to Cook et al. [9]. Cryogenicground Micronised Rubber Powder (at $<74 \mu \mathrm{m}$ denoted MRP074) and ambient-ground Crumb Rubber Powder (at $<400 \mu \mathrm{m}$ denoted CRP400) were compared. The effect of the interface morphology of RRP (MRP074 or CRP400) on tear strength and abrasion resistance in the elastomeric compound will be discussed.

\section{Experimental}

\subsection{Materials}

The rubber matrices were NR or BR compounds and NR/BR blend systems (70/30 ratio). The NR/BR ratio of 70/30 was selected [15] to balance properties such as abrasion, strength, fatigue and crack growth resistance for tyre tread formulation. Driven by their targeted properties, other authors have used NR/BR ratios of $50 / 50[16,17]$ or $60 / 40$ [18]. The NR was Standard Malaysian Rubber (SMR) 10. BR was cis1,4 polybutadiene rubber (Europrene Neo cis-BR-40). Crumb rubber powder (CRP400), entirely sourced from truck tyre at 40 mesh $(\sim 400 \mu \mathrm{m})$ particle size, was supplied by Crumb Rubber Ltd (Plymouth, UK). Micronised Rubber Powder (MRP-Polydyne ${ }^{\mathrm{TM}} 200$ ), also recycled material from truck tyre at 200 mesh (74 $\mu \mathrm{m}$ ), was supplied by Lehigh Technologies (Georgia, USA). The CRP400 and MRP074 recycled materials were from different batches of tyres. Other chemical ingredients used were of commercial grade (Table 1). For carbon-black (CB) filled compound, CB N234, 30 pphr was incorporated in NR, BR and NR/BR blend compound. Higher loading of $\mathrm{CB}$
Table 1. Formulation containing recycled rubber powder (in pphr).

\begin{tabular}{|l|c|c|c|}
\hline \multicolumn{1}{|c|}{ Masterbatch } & 0 & 10 pphr & 30 pphr \\
\hline Rubber (NR, BR or NR/BR blends) & 100 & 100 & 100 \\
\hline Zinc oxide & 3.5 & 3.5 & 3.5 \\
\hline Stearic acid & 2.5 & 2.5 & 2.5 \\
\hline Antilux 654 wax & 1 & 1 & 1 \\
\hline 6PPD ${ }^{1}$ antioxonant & 2.5 & 2.5 & 2.5 \\
\hline Flectol TMQ ${ }^{2}$ antioxidant & 1 & 1 & 1 \\
\hline MRP074/CRP400 & 0 & 10 & 30 \\
\hline
\end{tabular}

${ }^{1} 6 \mathrm{PPD}: N$-1,3-dimethylbutyl- $N^{\prime}$ phenyl-p-phenylenediamine

${ }^{2} \mathrm{TMQ}:$ 2,2,4-trimethyl-1,2-dihydroquinoline

N234, at 50 pphr was only prepared for the MRP074filled NR/BR blend compound. The curatives, 1.2 parts per hundred rubber [pphr] sulphur and $1 \mathrm{pphr}$ TBBS ( $N$-tert-butyl-2-benzothiazole sulphenamide), were added during final mixing. All rubber and chemical ingredients were supplied by Tun Abdul Razak Research Centre (TARRC), Brickendonbury, UK.

\subsection{Characterisation of recycled rubber powder (RRP)}

The RRP (CRP400 or MRP074) specimens were gold coated prior to Scanning Electron Microscopy (SEM) to avoid electrical charging. The morphology of the untreated RRP was observed in a JEOL JSM-6610 SEM, operating at $15 \mathrm{kV}$ accelerating voltage.

The RRP was analysed using Thermogravimetric Analysis (TGA) and Fourier Transform Infrared (FTIR) spectroscopy. Prior to analysis, samples were extracted in hot acetone overnight to remove low molecular weight polar substances such as remnant accelerator and curatives [19]. TGA analysis was carried out using PerkinElmer Pyris1. Extracted samples of approximately $10-15 \mathrm{mg}$ were heated from ambient temperature at $30^{\circ} \mathrm{C} / \mathrm{min}$ in a nitrogen atmosphere, before switching to oxygen atmosphere at around $550^{\circ} \mathrm{C}$. For the FTIR, portions of each extracted sample were pyrolysed in a furnace in test tube under standards conditions at $515 \pm 10^{\circ} \mathrm{C}$ and the released liquid analysed using a PerkinElmer Spectrum 100 FT-IR Spectrometer.

\subsection{Mixing process}

NR was masticated to reduce the viscosity to a nominal range of 60 Mooney units $\left(\mathrm{ML}(1+4)\right.$ at $\left.100^{\circ} \mathrm{C}\right)$, using a Bridge cracker mill, $(\varnothing 406 \mathrm{~mm} \times 508 \mathrm{~mm}$ length) then a two-roll mill (Francis Shaw- $50 \mathrm{~kg}$ capacity). Three master batches of each NR, BR or NR/BR compound were prepared using a Polylab 
2000E internal mixer $\left(390 \mathrm{~cm}^{3}\right.$ and fill factor of 0.75 for unfilled and 0.72 for $\mathrm{CB}$ filled compound). For NR/BR blend compound, the raw NR and BR were mixed simultaneously before addition of carbon black, RRP and other compounding ingredients. The masterbatch mixing was carried out with a starting temperature of $40^{\circ} \mathrm{C}$ and a rotor speed of $80 \mathrm{rpm}$ for unfilled or $60 \mathrm{rpm}$ for carbon-black filled compounds. Total mixing time for unfilled compound was about $5 \mathrm{~min}$ and carbon-filled compound was $6.5 \mathrm{~min}$, except for the carbon black-filled BR which required a slightly extended mix time of $7 \mathrm{~min}$. The masterbatches were allowed to cool overnight before the curatives were added separately using a two-roll mill. When the band was formed on the mill, about 3 rolling cuts were performed from each side of rubber. The rubber was then rolled 3 times on a tight nip. Each mix was then sheeted out at approximately 4-5 mm thick. The NR/BR compound with $50 \mathrm{pphr}$ carbon black was prepared using a Farrel OOC Banbury internal mixer $\left(4300 \mathrm{~cm}^{3}\right.$ and a fill factor of 0.75) but the MRP074 was added subsequently in a Farrel BR Banbury internal mixer $\left(1570 \mathrm{~cm}^{3}\right.$ and a fill factor of 0.75).

\subsection{Test specimen preparation}

The curing characteristics of the samples containing RRP were obtained at $160^{\circ} \mathrm{C}$ for $30 \mathrm{~min}$, using a Monsanto MDR 2000 rheometer with $0.5^{\circ}$ arc in accordance to BS ISO 6502:2016 standard. Compression moulding of test specimens from each mix used a Bradley and Turton Limited (Kiddermaster, United Kingdom) steam press at $160^{\circ} \mathrm{C}$ with $8 \mathrm{MPa}$ pressure. The $229 \mathrm{~mm}$ square by $2 \mathrm{~mm}$ thick sheets and DIN abrasion specimens (cylindrical discs of $\varnothing 15 \mathrm{~mm}$ and $8 \mathrm{~mm}$ thickness) were moulded using their respective optimum cure time, $t_{95}$ (time at $95 \%$ of the maximum torque rise), while the Shore A hardness button (a cylindrical disc of $\varnothing 25 \mathrm{~mm} \times 6 \mathrm{~mm}$ thickness) and Akron abrasion moulded discs (ø64 mm× $12.5 \mathrm{~mm}$ thick) with a centre hole of $\varnothing 12.7 \mathrm{~mm}$ were cured at $t_{95}+5$ mins.

\subsection{Mechanical properties}

Tear strengths were determined according to ISO 341:2015 (Method C for crescent tear). Crescent tear test specimens were cut from a $2 \mathrm{~mm}$-thick moulded sheet. An Instron 5567 universal testing machine with a $1 \mathrm{kN}$ load cell was used operating at crosshead speed of $500 \mathrm{~mm} / \mathrm{min}$ for the tear test. The tear strength was taken as the maximum force required for tearing of the specimen, divided by the thickness of the test piece using the median force recorded from five specimens. The Shore A hardness measurement was conducted in accordance to BS ISO 7619-1:2010. The median of five readings was recorded from both the tear and the hardness tests with an average then taken for the two hardness buttons.

The DIN abrasion resistance (BS ISO 4649:2010) was measured by abrading the rotating moulded piece across the surface of an abrasive sheet prepared to the specification in the standard mounted to a revolving drum $(40 \mathrm{rpm})$ at a constant force $(10 \mathrm{~N})$ and speed $(0.32 \mathrm{~m} / \mathrm{s})$. The abraded distance was about $40 \mathrm{~m}$. Each compound was tested with 3 replicates. The Akron Abrasion Laboratory wear testing used BS 903: A9: 1988 (Method B) as guidance for an in-house procedure. The position of the samples was set to a slip angle of $15^{\circ}$. Carborundum and Fuller's earth dust (2:1) were applied to remove debris and stickiness. The specimens were pre-abraded for 500 revolutions before testing and repeated 5 times at 1000 revolutions to achieve stable conditions. The weight loss (in $\mathrm{mg}$ ) after each 1000 revolutions and the average of the third-to-fifth measurements was recorded. The abrasion resistance for Akron and DIN is expressed as volume loss which was calculated from the weight loss and the density of the compound. The ratio of the sample weight in air and the volume (sample weight difference in the water and in air) was determined for density measurement.

\subsection{TEM 'network visualisation' sample preparation}

Samples of approximately $10 \times 4 \times 2 \mathrm{~mm}$ were cut from dumbbell specimens and wrapped into $40 \times 50 \mathrm{~mm}$ lens tissue and labelled accordingly. The selected samples were acetone extracted at $56^{\circ} \mathrm{C}$ using a Soxhlet-extraction apparatus overnight then dried under the fume hood to remove residual solvent before further drying in a vacuum oven overnight. The samples were cut to $4 \times 5 \mathrm{~mm}$ and put into a small test tube with $3 \mathrm{ml}$ of pre-mixed modified [14] styrene solution containing about $30-100 \mathrm{mg}$ benzoyl peroxide (cure initiator) and 50-200 mg di- $n$-butyl phthalate (DBP) (plasticiser) and allowed to swell to equilibrium over 1 to 2 days. The swollen samples (triplicates) were then further trimmed before encapsulation in a gelatine capsule with fresh styrene solution, as described above. These capsules were heated 
to about $50^{\circ} \mathrm{C}$ inside a metal block to polymerise the styrene. After about 7 days, the samples were hard enough for TEM sectioning.

Ultra-microtome $(\sim 100 \mathrm{~nm})$ sections of the samples were prepared using a RMC PowerTome $\mathrm{PC}$ at room temperature with a diamond knife. The sections were floated on a water-filled trough and relaxed with xylene vapour before collecting on TEM grids. Sections were then stained with osmium tetroxide $\left(\mathrm{OsO}_{4}\right)$ vapour for one hour and observed using a Philips CM12 TEM operating at $80 \mathrm{kV}$ to reveal the rubber network. TEM micrographs were acquired at higher magnifications using JEOL 1400 TEM at $120 \mathrm{kV}$.

\section{Results and discussion}

\subsection{Characterisation of raw recycled rubber powder}

Figure 1a shows the morphology of micronised powder rubber (MRP074) from the cryogenic production with nominal particle size of $74 \mu \mathrm{m}$ (Lehigh Technologies product specification). It is obvious that the structure of cryogenic powder from waste tyres is macroscopic smooth and angular, consistent with reports from other authors $[4,20]$. The morphology of ambient crumb rubber (CRP400) has a mainly rough crumble texture with some smooth surfaces as shown in Figure 1b.

The composition analysis from TGA, complemented by FTIR spectroscopy, is given in Table 2 . The polymer ratios in NR/Styrene Butadiene Rubber (SBR)/BR RRP are based on calibration curves using SBR with $23.5 \%$ styrene. The identification of NR to SBR/BR polymer ratio in both powders is about $80: 20$ by weight (NR:SBR/BR). SBR and BR provide similar structure in FTIR footprint, so this method cannot

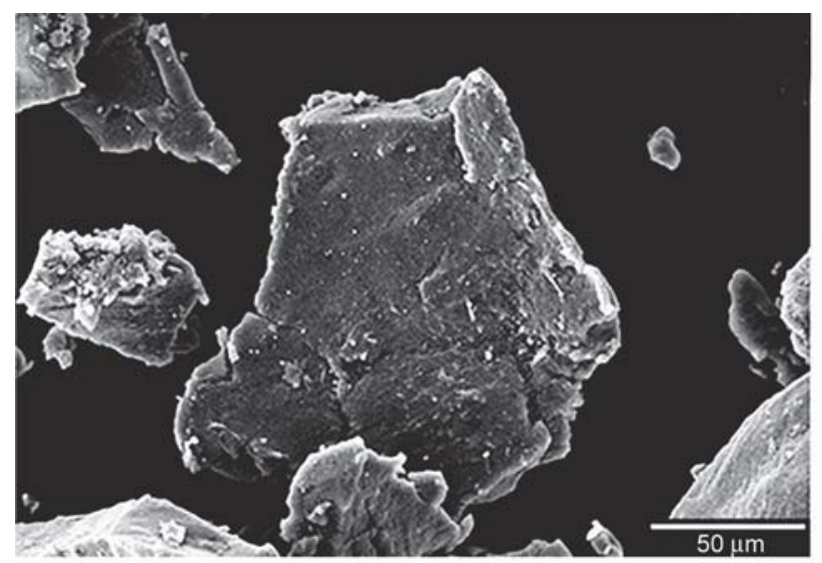

a)

Figure 1. (a) Micronised powder rubber (MRP074) from cryogenic method ( $74 \mu \mathrm{m})$, (b) Crumb rubber (CRP400) from ambient ground tyre $(\sim 400 \mu \mathrm{m})$

Table 2. Composition of recycled rubber powder after analysis.

\begin{tabular}{|l|r|r|c|}
\hline \multicolumn{4}{|c|}{$\begin{array}{c}\text { Composition } \\
\text { [wt\%] }\end{array}$} \\
\hline & CRP & \multicolumn{1}{|c|}{ MRP } & Change from CRP \\
\hline Rubbers (NR/SBR/BR) & 60.9 & 59.6 & $(-1.3)$ \\
\hline Carbon & 28.8 & 27.2 & $(-1.6)$ \\
\hline Ash & 5.0 & 7.6 & $(+2.6)$ \\
\hline Extract & 5.3 & 5.6 & $(+0.2)$ \\
\hline
\end{tabular}

distinguish between them. The main composition is not significantly different except for MRP074 having slightly higher ash content than CRP400.

\subsection{Cure characteristics}

Figure 2 shows a comparison of the change in torque, $\Delta M\left(\Delta M=\right.$ maximum torque $\left(M_{\mathrm{H}}\right)-$ minimum torque $\left.\left(M_{\mathrm{L}}\right)\right)$ for MRP074 or CRP400 loading of unfilled or carbon black-filled NR, BR or NR/BR compound. The $\Delta M$ value indicates the crosslink density and stiffness of the rubber vulcanisates. Hence, the addition of up to $30 \mathrm{pphr}$ RRP decreases the crosslinking of unfilled BR compound. These results agree with work by Gibala and Hamed [21] who found that migration of sulphur from the virgin compound to the RRP leads to further crosslinking of the RRP, while decreasing the crosslinking of the matrix. Overall stiffness of RRP filled compound is dominated by the matrix which reduces $\Delta M$. For $\mathrm{BR}$, the longer curing time allows more diffusion of curatives from virgin BR to the RRP phase which could explain the much larger drop in $\Delta M$.

The effect on $\Delta M$ of either CRP400 or MRP074 up to $30 \mathrm{pphr}$ loadings is marginal for NR and NR/BR blends. It is assumed that the migration is constrained by the fast curing of the NR compound. Competing

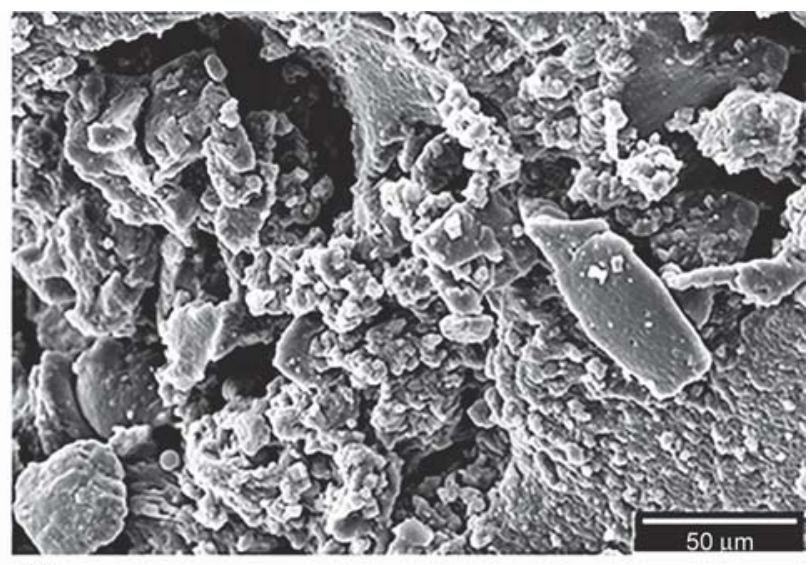

b) 

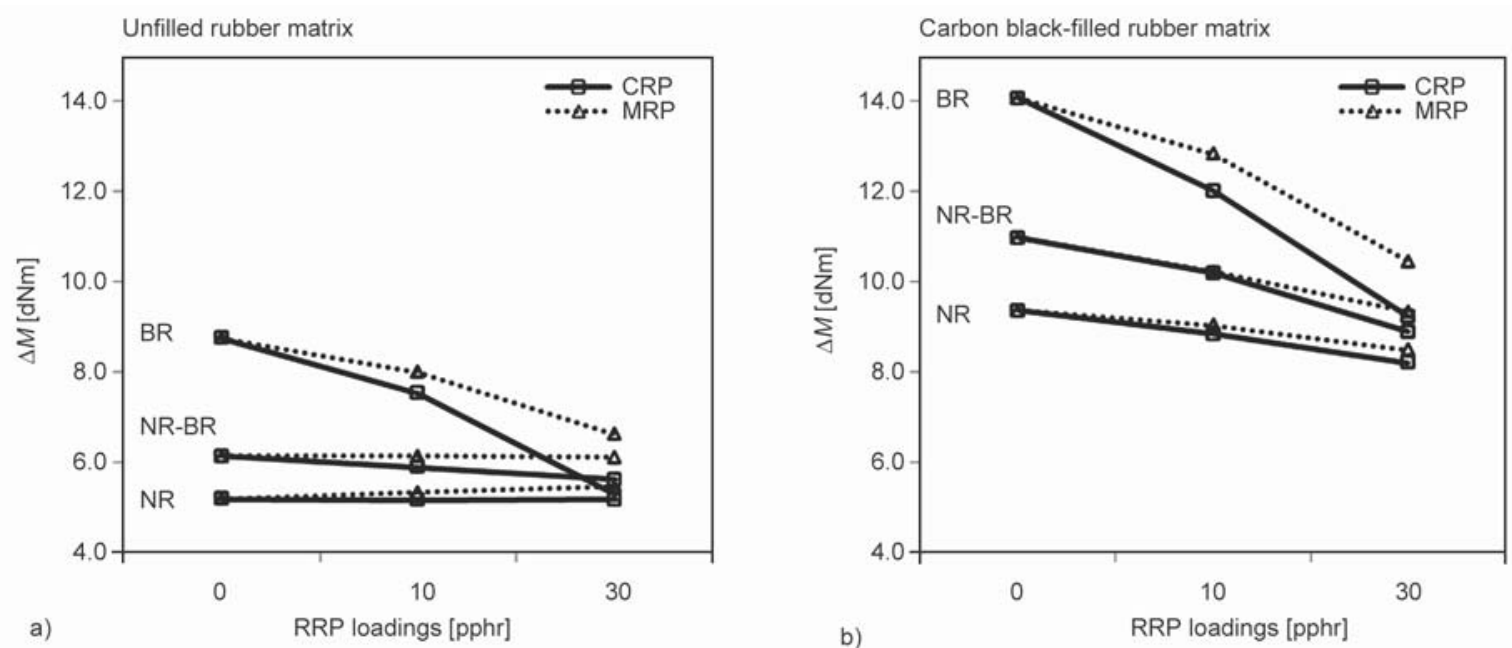

Figure 2. Comparison of $\Delta M$ for MRP074 or CRP400 loading of a) unfilled, and b) carbon black-filled NR, BR and NR/BR compound.

factors between reduction of crosslinking and stiffening effect of RRP (original composition was NR/ BR filled carbon black) explains the trends in torque behaviour of NR or NR/BR compound. At similar loadings, MRP074 filled NR/BR exhibits higher torque than CRP400 filled compound. The possible reason may be attributed to smaller particles of MRP074 which provide slightly more reinforcement compared to CRP400.

As expected, in carbon black filled compound, the addition of carbon black increases $\Delta M$ through physical absorption and/or chemical bonding between rubber molecules and $\mathrm{CB}$ surfaces [22]. The $\Delta M$ reduction is more obvious in carbon-filled than unfilled NR or NR/BR compound. Modifying the formulation by increasing sulphur and reducing accelerator may restore crosslink density to be comparable to the control compound [2].

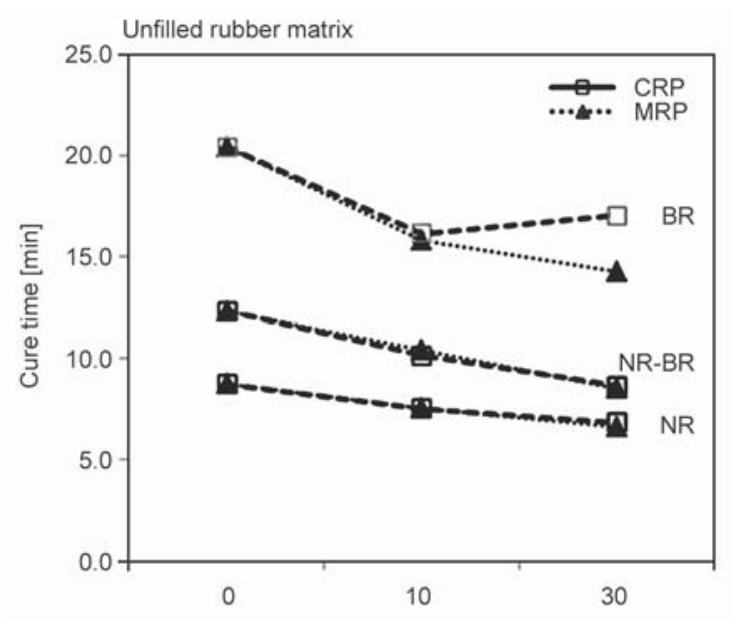

a)

RRP loadings [pphr]
Gibala and Hamed [21] additionally found accelerator fragments bound to the RRP network can be released due to the sulphur migration into the rubber crumb. This reduces the cure time of the compounds containing CRP400 or MRP074 as shown in Figure 3 for unfilled and carbon-black filled NR, BR or NR/BR compound with the single exception of CRP400-filled BR at $30 \mathrm{pphr}$ loading. An observed increase in the cure time suggests that the migration in CRP400 is faster than MRP074-filled BR leading to rapid depletion of the accelerator fragments in the blends. In carbon-black filled compound, the accelerator fragments may be absorbed by the carbon black [23] leading to marginal reduction of the cure time compared to the unfilled compound. The trend for CRP400 or MRP074 filled compound is similar, thus the cure time for NR, BR and NR/BR blend compound was not affected by the particle size of the RRP.

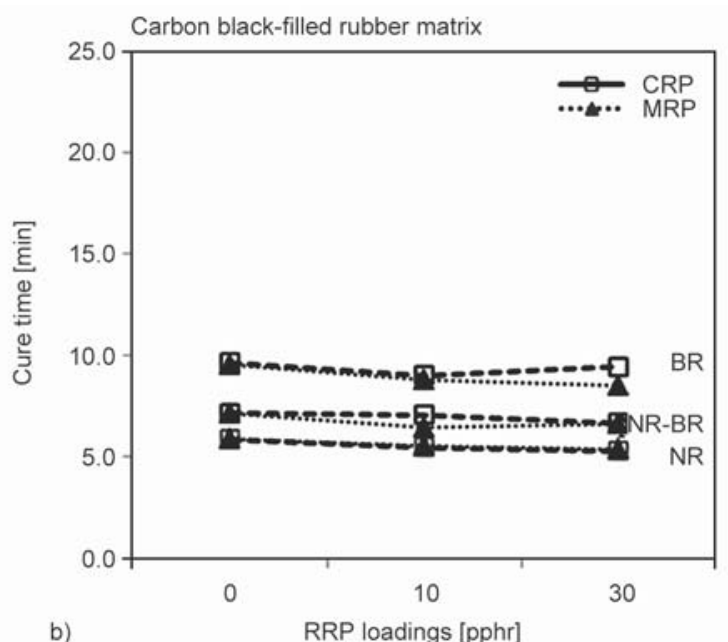

b)

RRP loadings [pphr]

Figure 3. Comparison of cure time for MRP074 or CRP400 loading of a) unfilled, and b) carbon black-filled NR, BR and NR/BR compound. 


\subsection{Interface bonding strength via TEM 'network visualisation'}

The MRP074 or CRP400 particles are seen as a matrix containing carbon black particles in all TEM micrographs. In the unstained micrograph of MRP074filled NR (Figure 4a) or BR (Figure 4c), a distinct line of small particles is visible at the interface between the MRP074 and the rubber matrix. The mesh structure of the rubber network can be distinguished from the polystyrene region in the stained samples. The $\mathrm{OsO}_{4}$ vapour staining method enhances contrast in regions of the network with different levels of unsaturation. The stained network causes the mesh structure to appear darker than the polystyrene region. The stained samples (Figure 4b, 4d) show several areas of the interface with currently unidentified particles, surrounded by 'polystyrene voids' present in NR and BR. The higher ash content (Table 2) in MRP074 composition may be related to these unknown particles. Further investigation is needed to confirm this assumption.

Higher magnification TEM micrograph sections of MRP074-filled NR or BR matrix interface containing

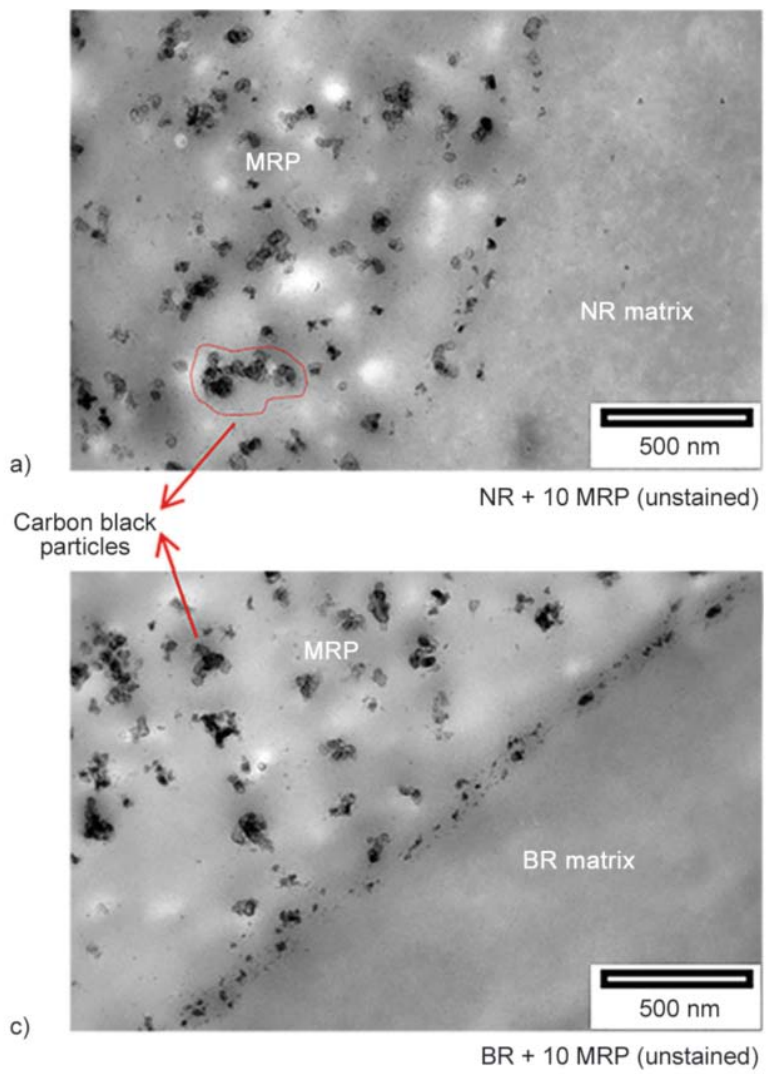

polystyrene 'voids' are highlighted (red line) in Figure 5 . The relatively weak interface interaction between rubber-MRP074 networks may enable the polystyrene to penetrate between the rubber and those particles. The number of these particles at the interface is assumed to increase with MRP074 content and create further stress concentrations, leading to debonding and eventually detachment of particles.

Figure 6 shows the TEM micrographs of stained CRP400-filled NR and BR. The convoluted surface of CRP400 (highlighted red line) is very pronounced in both NR and BR compound. Small particles are observed at the interface of MRP074-filled NR or BR but are not visible at the interface of CRP400 filled NR or BR. The interface morphology showed that CRP400 provides more developed structure or 'convoluted interface' which probably suggests stronger interface strength of the CRP400 with the rubber matrix. The strong physical bonding between the rubber matrix and CRP400 network is clearly associated with the convoluted shape compared with the macroscopic smooth surface structure of MRP074 particles. These findings agree with previous publications

b)

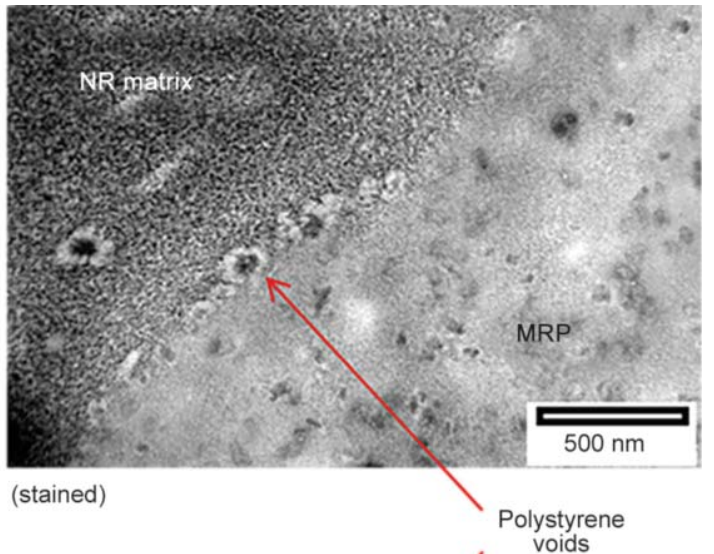

d)

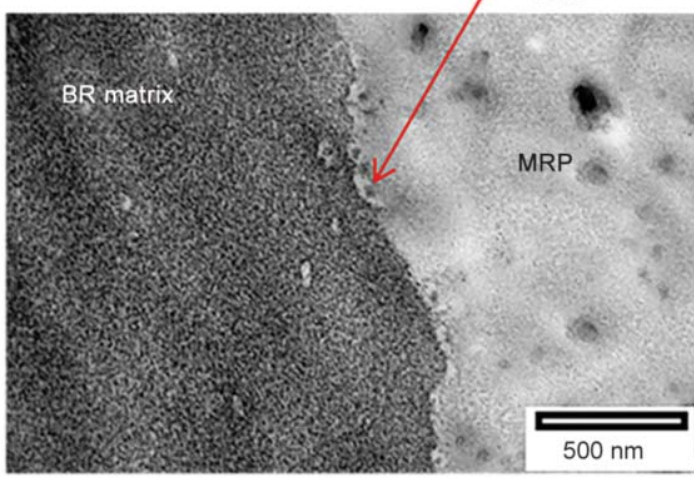

(stained)

Figure 4. TEM 'network visualisation' micrographs of (a) NR+10 pphr MRP074 (unstained), (b) NR+10 pphr MRP074 (stained), (c) BR+10 pphr MRP074 (unstained), (d) BR+10 pphr MRP074 (stained) sectioned from unfilled rubber vulcanisate. 


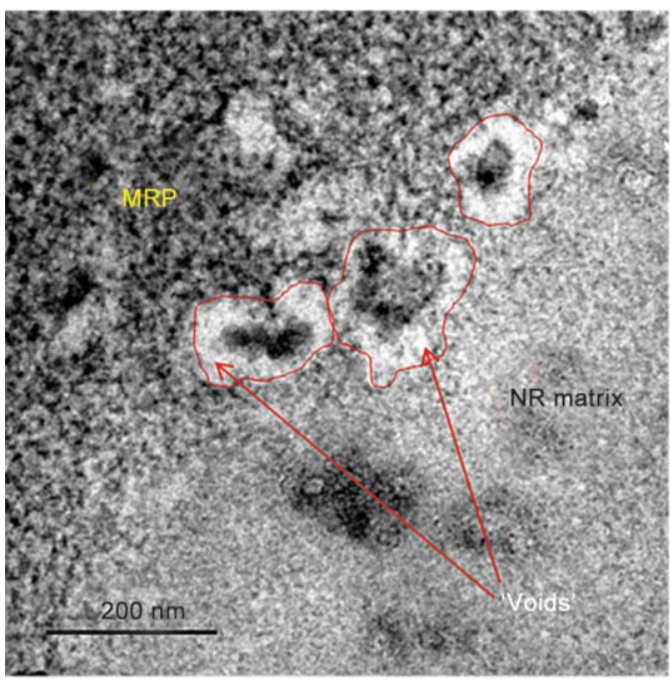

a)

$\mathrm{NR}+10 \mathrm{MRP}$

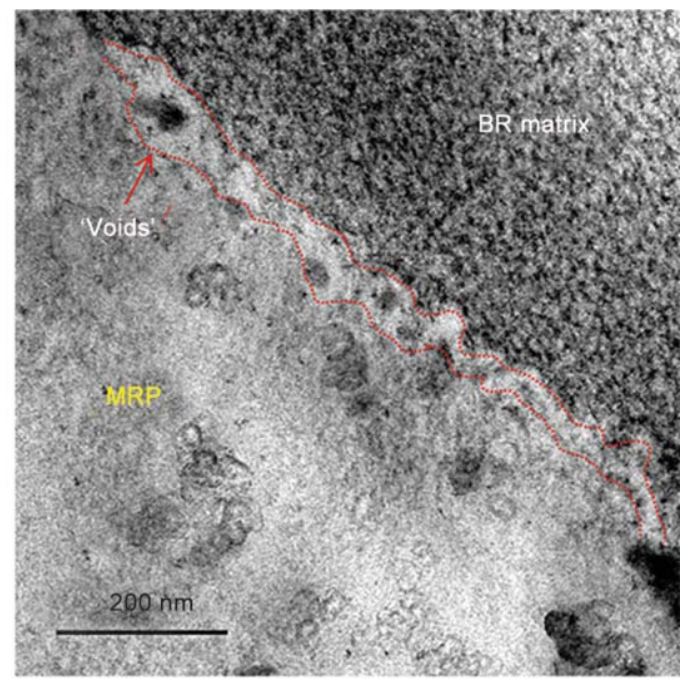

b)

$\mathrm{BR}+10 \mathrm{MRP}$

Figure 5. TEM 'network visualisation' micrographs of (a) NR+10 pphr MRP074 (stained), (b) BR+10 pphr MRP074 (stained) sectioned from unfilled rubber vulcanisate.

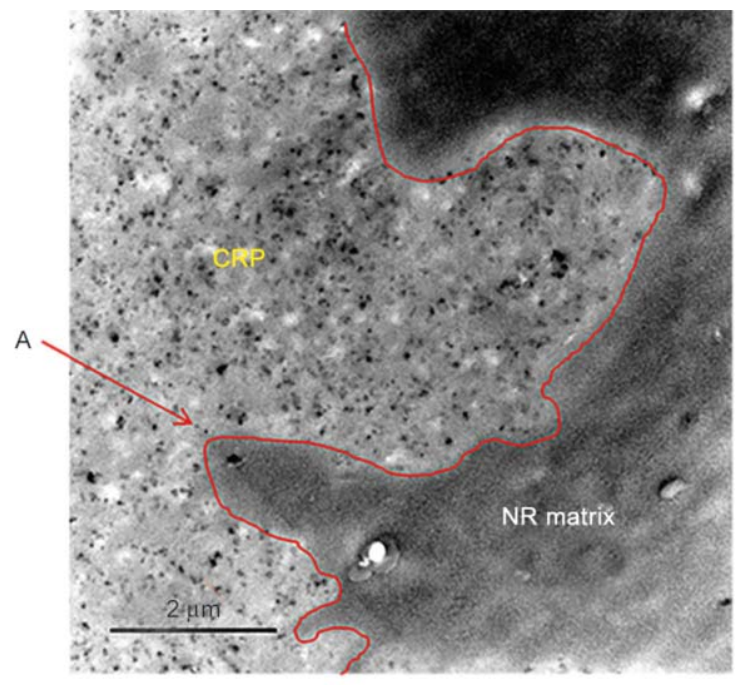

a)

$\mathrm{NR}+10$ pphr CRP

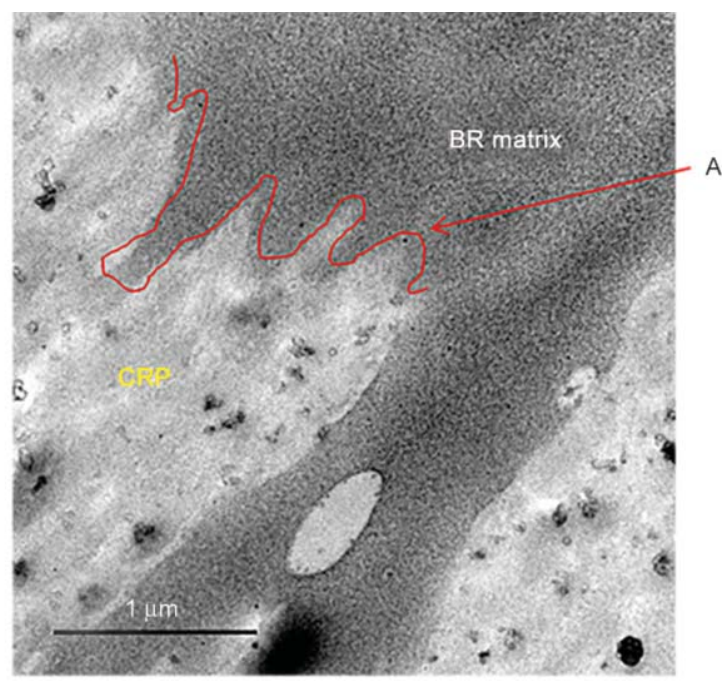

b)

$\mathrm{BR}+10 \mathrm{pphr}$ CRP

A - convoluted shape

Figure 6. TEM ‘network visualisation' micrographs of stained (a) NR+10 pphr CRP400, (b) BR+10 pphr CRP400 sectioned from unfilled rubber vulcanisate.

$[4,5]$. The relationship of the interface morphology on tear strength and abrasion resistance will be discussed in sections 3.4 and 3.5-3.6, respectively.

\subsection{Crescent (propagation) tear strengths}

Buist and Kennedy [24] proposed two different types of tear test: (i) angle tear to indicate resistance to tear initiation; (ii) crescent tear to determine the resistance to crack propagation. In this work, the crescent tear test measures the resistance to crack propagation. Tear strength $(T)$ was measured from the maximum force obtained from load-deflection graphs divided by the specimen thickness.
Table 3 displays the hardness and tear strength based on crescent tear pieces of RRP filled NR, BR or NR/BR blend in unfilled or carbon-filled compound. The hardness showed little change with the addition of 10 pphr of either CRP400 or MRP074. The incorporation of $30 \mathrm{pphr}$ RRP slightly increases the hardness for NR and NR/BR blend compound. The reduction in crosslink density, attributed to the sulphur migration discussed earlier, decreased the hardness of the BR compound. The crescent type tear test, measures the maximum force required to propagate a $1 \mathrm{~mm}$ initial cut through the whole specimen. The resistance to crack propagation in unfilled compound 
Table 3. Hardness and tear strength for RRP-filled NR, BR and NR/BR blend compound; unfilled and CB-filled compound.

\begin{tabular}{|l|c|c|c|c|}
\hline & $\begin{array}{c}\text { Hardness } \\
{[\text { Shore A] }} \\
\text { Unfilled }\end{array}$ & $\begin{array}{c}\text { Tear strength } \\
{[\mathbf{k N} / \mathbf{m}] \pm \text { SD }} \\
\text { Unfilled }\end{array}$ & $\begin{array}{c}\text { Hardness } \\
{[\text { Shore A] }} \\
\text { CB-filled-30 pphr }\end{array}$ & $\begin{array}{c}\text { Tear strength } \\
{[\mathbf{k N} / \mathbf{m}] \pm \text { SD }^{*}} \\
\text { CB-filled-30 pphr }\end{array}$ \\
\hline NR/0 & 32 & $32.0 \pm 0.9$ & 48 & $94.5 \pm 23.0$ \\
\hline NR/10-CRP400 & 33 & $24.8 \pm 1.6$ & 49 & $75.5 \pm 16.0$ \\
\hline NR/30-CRP400 & 35 & $14.6 \pm 2.1$ & 50 & $60.1 \pm 13.0$ \\
\hline NR/10-MRP074 & 34 & $23.0 \pm 3.1$ & 50 & $79.3 \pm 14.0$ \\
\hline NR/30-MRP074 & 36 & $10.5 \pm 1.7$ & 55 & $14.1 \pm 9.0$ \\
\hline BR/0 & 41 & $7.7 \pm 0.9$ & 54 & $16.9 \pm 1.3$ \\
\hline BR/10-CRP400 & 41 & $7.2 \pm 0.6$ & 52 & $35.9 \pm 8.3$ \\
\hline BR/30-CRP400 & 38 & $6.9 \pm 0.9$ & 53 & $16.4 \pm 0.8$ \\
\hline BR/10-MRP074 & 41 & $8.8 \pm 0.2$ & 52 & $25.4 \pm 6.0$ \\
\hline BR/30-MRP074 & 40 & $12.4 \pm 1.0$ & 52 & $69.4 \pm 9.3$ \\
\hline NR-BR/0 & 35 & $11.2 \pm 1.2$ & 53 & $62.9 \pm 11.8$ \\
\hline NR-BR/10-CRP400 & 35 & $11.3 \pm 0.8$ & 52 & $61.5 \pm 17.0$ \\
\hline NR-BR/30-CRP400 & 36 & $8.8 \pm 0.8$ & 51 & $73.9 \pm 11.2$ \\
\hline NR-BR/10-MRP074 & 36 & $9.8 \pm 0.4$ & & $66.0 \pm 16.4$ \\
\hline NR-BR/30-MRP074 & 37 & & & \\
\hline
\end{tabular}

*standard deviation

is ranked NR $\gg \mathrm{NR} / \mathrm{BR}>\mathrm{BR}$ compound. This may be attributed to the strain-induced crystallisation and 'crack tip blunting' behaviour [25] of NR during tearing.

The addition of up to $30 \mathrm{pphr}$ MRP074 or CRP400 in unfilled NR caused a significant drop in the tear strengths (Table 3). Once the crack has initiated in MRP074 filled NR compound, the crack propagation resistance reduces. The crack resistance is also reduced for unfilled with MRP074 or CRP400 NR/BR at 10 or $30 \mathrm{pphr}$ loadings but the reduction was smaller than in NR. Pittolo and Burford [26] showed that the tear strength of recycled material is dependent on both the filler hardness and the filler-matrix bonding. The structure and weak interface between MRP074 and matrix in unfilled NR discussed earlier contributed to the lower tear strength compared to CRP400 filled NR. Correspondingly, CRP400-NR/BR compound showed higher tear strength compared to MRP074-NR/BR.

In BR, the opposite was observed. The crack propagation resistance of BR increases with increasing MRP074 or CRP400 concentration in both unfilled and CB-filled BR, within the tested range of up to 30 pphr. In unfilled compound, CRP400-BR had lower tear strength compared to MRP074 containing BR at 30 pphr of MRP074. The effect of smaller particle size is dominant in $\mathrm{BR}$ at higher concentration of MRP074. Despite the weak interface interaction of MRP074 networks, an increase in crescent tear propagation strength for BR compound is probably due to a combination of factors such as:

- an improved bonding between the BR phase and crosslinked-MRP074,

- tear deviation,

- probably a reduced crosslink density matrix,

- some contribution of hysteresis within the filler.

The addition of carbon black $(\mathrm{CB})$ resulted in a heterogeneity in the rubber matrix. Hence, CB-filled compound displays a higher scatter in the results compared to the unfilled compound. The addition of carbon black in NR or NR/BR control compounds produces wide scatter even without the MRP074 incorporation. This requires the optimisation of the mixing cycles and the addition of small quantities of processing oils. Uniformly dispersed curatives, filler and other ingredients in the matrices need to be incorporated in the continuous phase to resist failure under various stress and strain conditions. These factors also need to be considered when incorporating MRP074 into any rubber matrix. Clarke et al. [27] concluded that a suitable mixing cycle could produce a fine textured morphology due to optimum filler dispersion. This results in blends with higher strength whereas the clustering in coarse morphology is more likely to introduce premature crack initiation and consequent early failure. A compromise in properties is usually a consequence of blending two rubbers. Blending NR with BR increases crack propagation. Despite the lower crack resistance in NR/BR blends 
compared to NR, BR has an excellent abrasion resistance, and blending with NR improved this property (see section 3.5).

The heterogeneity created by the carbon black filler retards the crack propagation of the NR, BR or NR/BR blend compound. Reinforcement of rubber matrix by the carbon black restricts the mobility of the rubber network. The breakup and reformation of filler network within the rubber chain during the fracture process involves energy dissipation, often referred to as mechanical hysteresis [28]. Hence, increased hysteresis is partly contributed to the enhancement of tear performance of carbon black filled compound than for unfilled rubber compound. Factors such as strain crystallisation, strength anisotropy, crack deviation and crack tip profiles are also reported [29, 30]. This compensates for the tear strength reduction of unfilled NR and NR/BR compounds containing MRP074 or CRP400. The crack propagation resistance of NR/BR (70/30 ratio) appears to be slightly improved giving similar performance to NR compound at equivalent ratio of $10 \mathrm{pphr}$ MRP074. The addition of carbon black to MRP074-filled compound tends to improve tear resistance more than CRP400-filled compound, which contradicts the result from the unfilled materials. However, considering the large scatter in the tear strength results (Table 3), the effect of MRP074 is not significantly different compared to CRP400 in CB-filled NR, BR or NR/BR blend compounds.

\subsection{Abrasion resistance}

The choice of abrasion test is critical for the performance evaluation of any new compound. In the present work, the effect of MRP074 and CRP400 on abrasion

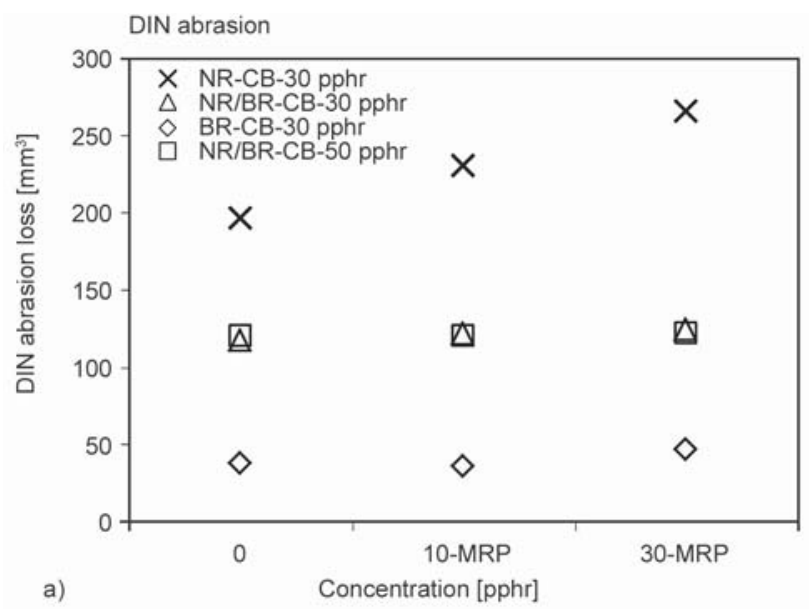

resistance will only be discussed for the carbon-black filled compounds. DIN or Akron abrasion tests were conducted. The DIN abrader uses more severe frictional forces than the Akron abrader. Elsewhere, Martin et al. [14] have demonstrated that the Akron abrasion test is more severe than normal tyre wear. Thus, laboratory tests may not replicate real world abrasion behaviour, especially for tyre applications due to various climate, road and driving conditions $[14,31]$. The following experiments demonstrate that Akron abrasion test could indicate the strength of interactions between rubber and filler particularly in NR/BR blends. A weak interaction or interface will provide starting point for crack initiation, and any further applied load or deformation will lead to rapid crack propagation.

The abrasion resistance results of NR, BR or NR/BR vulcanisates with different MRP074 loadings are displayed in Figure 7. The outstanding performance of BR can be seen on both abrasion tests, which is consistent with the literature [32]. Combining both the excellent abrasion resistance of BR and good processing properties of NR produces ideal blends especially for truck and passenger tyre applications. Overall the trend in abrasion loss of MRP074-filled NR or BR is similar for both abrasion tests, but differs for NR/BR blends. From DIN and Akron abrasion tests, the volume loss increases with the increase in MRP074 loadings in NR. There is a negligible increasing trend in volume loss for NR/BR compound, using DIN abrasion test of MRP074 filled compound at 10 or $30 \mathrm{pphr}$ loadings. However, much higher increases in abrasion loss in Akron abrasion test at similar MRP074 loadings are shown in Figure 7b. The BR compound shows a small decrease in abrasion

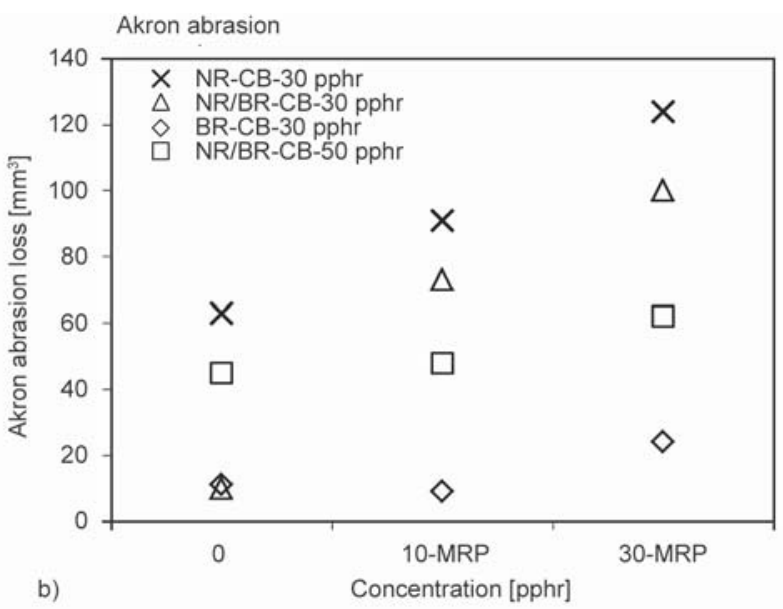

Figure 7. Comparison of (a) DIN and (b) Akron abrasion resistance of MRP074 carbon-black filled NR, BR or NR/BR compound (Note: The $Y$-axis full scale in (b) is less than half that in (a)). 
loss for both DIN and Akron abrasion indicating good bonding of MRP074 with BR compound at $10 \mathrm{pphr}$. At $30 \mathrm{pphr}$ of MRP074 loadings, there is a small increase in the volume loss for both tests.

The addition of carbon black loading of $50 \mathrm{pphr}$ in $\mathrm{NR} / \mathrm{BR}$ compound improved the abrasion resistance of MRP074-filled material within the tested range of up to $30 \mathrm{pphr}$ MRP074. This seems true for Akron abrasion but not for DIN abrasion. The strong interface bonding between NR and BR is well documented [27] and plays an important part in the ability of blends to withstand deformation. However, the Akron abrasion test demonstrates that the interaction is not strong enough to sustain material integrity as indicated by higher losses with MRP074 at up to $30 \mathrm{pphr}$. The DIN abrasion test could not easily detect the changes in the matrix introduced by MRP074 particularly in carbon-filled NR/BR (Figure 7a). This is due to Akron and DIN having different mechanisms. DIN is predominantly a mixture of tensile-tearing and cutting (frictional rubbing) while Akron is microscale tearing and fatigue [15]. Despite the more mechanical abrasion mechanism for the laboratory tests, the actual tyre wear may involves chemical changes, probably oxidative. Although prediction from laboratory measurements has yet to be achieved, Akron abrasion is reported [31] to correlate with fatigue properties and is thus probably more useful in material evaluation.

The control compound containing $50 \mathrm{pphr} \mathrm{CB}$ showed higher volume loss compared to $30 \mathrm{pphr} \mathrm{CB}$ indicating that dispersion is also one of the factors affecting abrasion resistance. Improving abrasion properties may also be possible through optimisation of the cure systems.

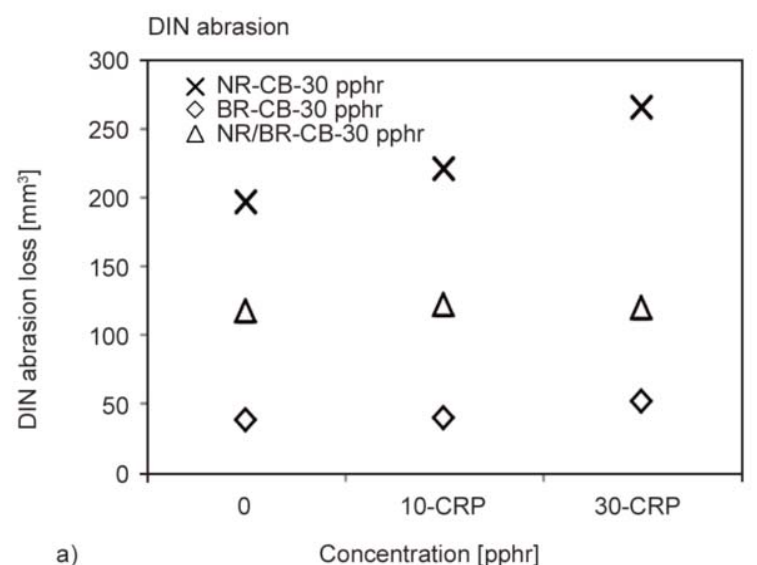

The weak interface in BR (Figure 5b) is only apparent at higher loadings of MRP074 (30 pphr) in both DIN and Akron abrasion. Similarly, for NR/BR blends (where the interface interaction of MRP074 and matrix was not studied), it may be assumed that the weakness is again present and reflected in the Akron abrasion result. However, this is not revealed by the DIN abrasion test.

\subsection{Abrasion resistance performance of MRP074 versus CRP400 filled compound}

The abrasion resistance results for NR, BR or NR/BR vulcanisates with different CRP400 loadings are displayed in Figure 8. Similar to MRP074-filled NR compound, an increasing trend in the volume loss for CRP400-filled NR within the tested range up to $30 \mathrm{pphr}$ for both DIN and abrasion tests is observed. Table 4 shows the comparison of DIN and Akron abrasion loss for MRP074 and CRP400. For NR or NR/BR blend compounds, the higher abrasion volume loss of finer MRP074 compared to larger CRP400 particles infers that the bonding between the rubber-filler interface is a more important for the abrasion results than the size of the RRP. A contrary result was found in MRP074-filled BR compound, where a decrease in volume loss was observed at $10 \mathrm{pphr}$ MRP074. Increasing volume loss was observed in BR as the concentration of CRP400 and MRP074 increases. In BR compound, the particle size dominates achieving higher abrasion resistance besides the interface bonding strength. Additional experiment for non-crystallising rubber would be needed to support this finding.

Similar to MRP074-filled compound, DIN and Akron abrasion test give similar trend of NR and BR

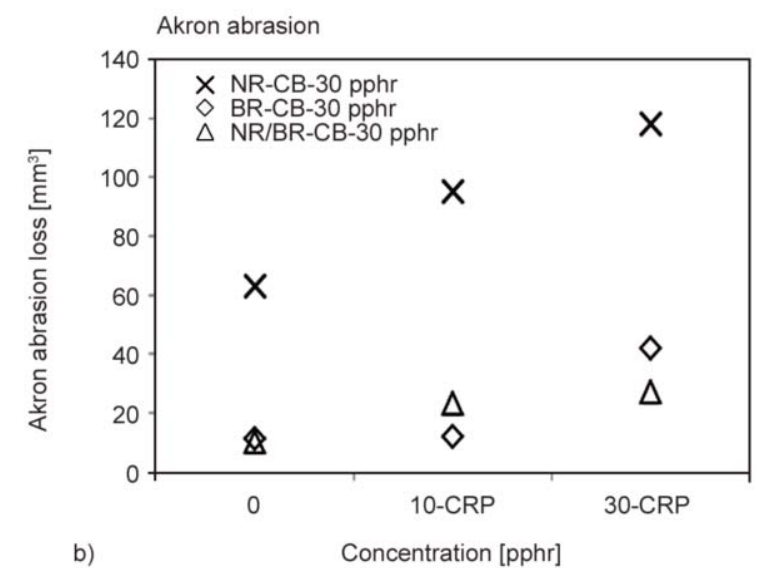

Figure 8. Comparison of (a) DIN and (b) Akron abrasion resistance of CRP400 carbon-black filled NR, BR or NR/BR compound (Note: The $Y$-axis full scale in (b) is less than half that in (a)). 
Table 4. Abrasion resistance of elastomer containing MRP074 or CRP400 using DIN and Akron abrasion.

\begin{tabular}{|c|c|c|c|c|c|}
\hline $\begin{array}{c}\text { Compound } \\
\text { [pphr] }\end{array}$ & \multicolumn{2}{|c|}{$\begin{array}{c}\text { Abrasion volume loss } \\
{\left[\mathbf{m m}^{3}\right]}\end{array}$} & $\begin{array}{c}\text { Compound } \\
\text { [pphr] }\end{array}$ & \multicolumn{2}{c|}{$\begin{array}{c}\text { Abrasion volume loss } \\
{\left[\mathbf{m m}^{3}\right]}\end{array}$} \\
\hline NR & DIN & Akron & BR & DIN & Akron \\
\hline 0 & 197 & 86 & 0 & 38 & 12 \\
\hline $10-$ MRP074 & 231 & 103 & $10-$ MRP074 & 36 & 25 \\
\hline $30-$ MRP074 & 266 & 131 & $30-$ MRP074 & 47 & 12 \\
\hline 0 & 197 & 86 & 0 & 38 & 40 \\
\hline 10 CRP400 & 221 & 99 & 10 CRP400 & 40 & 52 \\
\hline 30 CRP400 & 266 & 115 & 30 CRP400 & DIN & Akron \\
\hline \hline NR/BR (70/30) & DIN & Akron & NR/BR (70/30) & 118 & 25 \\
\hline 0 & 118 & 25 & 0 & 122 & 38 \\
\hline $10-M R P 074$ & 122 & 79 & $10-C R P 400$ & 120 & 45 \\
\hline $30-M R P 074$ & 125 & 105 & $30-C R P 400$ & & \\
\hline
\end{tabular}

compound and differs for NR/BR blends containing CRP400. DIN abrasion showed a small increasing volume loss with almost negligible difference between 10 and $30 \mathrm{pphr}$ loadings relative to the control compound, while Akron abrasion test shows a steady increase in the abrasion loss. CRP400-filled compound has better abrasion resistance indicated by Akron testing compared to MRP074-filled compound.

Ayyer et al. [20] reported that the cryogenic particles had higher surface area due to higher content of finer particles (compared to ambient particles) at all the nominal particle sizes. Elsewhere [33], the rough textures of ambient particles exhibited higher surface area than cryogenic particles at similar particle size distribution. Different textures between MRP074 and CRP400 result from different methods of grinding as described in previous report [4]. This work uses MRP074 with smaller particle size compared to CRP400. Although the estimation of the total surface area based on a spherical smooth particle model suggested that MRP074 have greater surface area compared to CRP400, the measurement could underestimate the convoluted surfaces which are beyond the reach of 2D measurements due to rough surface of CRP400.

In various carbon black filled elastomers, according to Hong et al. [34], the rates of abrasion decreased with increasing the surface area and with developing structure of the filler. Although the CRP400 particles are larger compared to MRP074, the convoluted structure provides better interfacial adhesion between CRP400 and carbon-black filled rubber matrix than MRP074 filled compound. This also infers that the rough structure of CRP400 may provide greater surface area than MRP074 filled compound which explain higher abrasion resistance of CRP400-filled NR or NR/BR than MRP074-filled compounds.

\section{Conclusions}

The weak interaction at the interface between MRP074 particles and the rubber network matrix was visualised as polystyrene 'voids' around particles, using the TEM 'network visualisation' technique. The less convoluted shape in the TEM micrographs of MRP074 over CRP400 were identified.

Crescent tear tests were used as an indication of crack propagation resistance in the rubber matrix. In this type of test, the adhesion between RRP and matrix is important. The effect of structure and weak interaction was confirmed by the lower tear strength in MRP074-filled matrix compared to CRP400-filled matrix in both NR and NR/BR blend compound. However, in BR, the particle size of MRP074 is more dominant than the structure which resulted in the opposite trend. For the carbon black filled compound, the weak interactions of MRP074 are not reflected in the tear strength results due to a high scatter in the data caused by the inhomogeneity and tear deviation by the carbon black filler. The carbon-black filler seems to compensate the weak interaction shown by MRP074 filler partly due to hysteresis.

Higher volume loss for NR, and for higher loadings of MRP074 (30 pphr) in BR, in both DIN and Akron abrasion tests were found. Other factors such as crosslinking density may be contributing to the higher abrasion loss due to the migration of sulphur from the pure rubber matrix to the MRP074. Despite the compensation of carbon black filler in tear strength, the Akron test appears to be able to characterise the 
possible weak interaction of MRP074 particularly in NR/BR blend matrix more effectively than the DIN abrasion test. The DIN and Akron abrasion resistance tests give two contrary trends for the NR/BR blends, while for NR and BR, DIN and Akron trends were similar. The CRP400-filled compound had better abrasion resistance, as indicated by Akron testing compared to MRP074-filled NR and NR/BR blend compound. The convoluted structure of CRP400 related to its larger surface area appears to be a more dominant factor than the particle size which contributes to better abrasion resistance than in MRP074filled compound. The abrasion resistance of the BR compound containing MRP074 filler however outperformed the CRP400-filled compound. In BR, the particle size seems to outweigh the structure factors which resulted in better abrasion resistance for the MRP074-filled compound.

The superior abrasion resistance of BR compound and carbon black loading compensates for the abrasion loss in NR/BR blends containing $10 \mathrm{pphr}$ of MRP074 and is comparable to NR compound. The sulphur migration affected the crosslink density of MRP074 or CRP400 filled matrix and was reflected in the cure characteristic of the rubber matrix. Likewise the tear and abrasion resistance of compounds containing MRP074 or CRP400 filled compound was lower than the control compound. Thus, further optimisation of the design formulation may be possible for MRP074/CRP400 at higher concentrations with consequent enhancement in these key properties. Future research plans include a study of long-term mechanical stability of the MRP074 or CRP400-filled rubber under cyclic fatigue loading conditions simulating potential real-world applications.

\section{Acknowledgements}

The authors gratefully acknowledge the financial support from the Malaysian Rubber Board and access to facilities at Tun Abdul Razak Research Centre (TARRC). The authors would like to thank Kenneth Halls, Paul Gladwin for mixing assistance, Stuart Cook, Andy Chapman and Jaymini Patel for technical support, Jonathan Clark for assistance on the preparation of 'network visualisation' samples, Robin Davis and Kathy Lawrence for microtome and transmission electron microscopy work, Collin Hull for composition analysis, Peter Bond from Plymouth Electron Microscopy Centre and equally all staff of Product evaluation and testing, TARRC for physical testing.

\section{References}

[1] Adhikari B., De D., Maiti S.: Reclamation and recycling of waste rubber. Progress in Polymer Science, 25, 909-948 (2000).

https://doi.org/10.1016/S0079-6700(00)00020-4

[2] Papp F. P.: Optimizing the use of micronized rubber powder made from end-of-life tire material. Rubber World, 246, 16-27 (2012).

[3] Phadke A. A., Chakraborty S. K., De S. K.: Cryoground rubber-natural rubber blends. Rubber Chemistry and Technology, 57, 19-33 (1984).

https://doi.org/10.5254/1.3535994

[4] Dierkes W.: Untreated and treated rubber powder. in 'Rubber recycling' (eds.: De S. K., Isayev A., Khait K.) CRC Press, Boca Raton, 127-154 (2005).

https://doi.org/10.1201/9780203499337.ch3

[5] Burford R. P., Pittolo M.: Characterization and performance of powdered rubber. Rubber Chemistry and Technology, 55, 1233-1249 (1982).

https://doi.org/10.5254/1.3535928

[6] Swor R. A., Jensen L. W., Budzol M.: Ultrafine recycled rubber. Rubber Chemistry and Technology, 53, 1215-1225 (1980). https://doi.org/10.5254/1.3535089

[7] Ma J-H., Zhang L-Q., Wu Y-P.: Characterization of filler-rubber interaction, filler network structure, and their effects on viscoelasticity for styrene-butadiene rubber filled with different fillers. Journal of Macromolecular Science Part B: Physics, 52, 1128-1141 (2013). https://doi.org/10.1080/00222348.2012.755441

[8] Schuster R. H., Meier J., Klüppel M.: The role of interphase in filler partition in rubber blends. Kautschuk Gummi Kunststoffe, 53, 663-674 (2000).

[9] Cook S., Cudby P. E. F., Tinker A. J.: Direct observation of crosslink distribution in vulcanized blends through visualizing the networks. in ' $142^{\text {nd }}$ Fall Meeting of the Rubber Division, Nashville, USA', Paper 3 (1992).

[10] Cook S., Cudby P. E. F., Tinker A. J., Bomal Y.: Network visualization of elastomer vulcanizates. in ' $156^{\text {th }}$ Fall Meeting of the Rubber Division, Orlando, USA', Paper 19 (1999).

[11] Tinker A. J.: Measurement of crosslink density in vulcanized blends. in 'Blends of natural rubber' (eds.: Tinker A. J., Jones K. P.) Chapman and Hall, London, 820 (1998).

https://doi.org/10.1007/978-94-011-4922-8_ 2

[12] Sarkawi S. S., Dierkes W. K., Noordermeer J. W. M.: Elucidation of filler-to-filler and filler-to-rubber interactions in silica-reinforced natural rubber by TEM network visualization. European Polymer Journal, 54, 118 127 (2014).

https://doi.org/10.1016/j.eurpolymj.2014.02.015 
[13] Ladouce-Stelandre L., Bomal Y., Flandin L., Labarre D.: Dynamic mechanical properties of precipitated silica filled rubber: Influence of morphology and coupling agent. Rubber Chemistry and Technology, 76, 145-159 (2003).

https://doi.org/10.5254/1.3547730

[14] Martin P. J., Brown P., Chapman A. V., Cook S.: Silica-reinforced epoxidized natural rubber tire treads Performance and durability. Rubber Chemistry and Technology, 88, 390-411 (2015).

https://doi.org/10.5254/rct.15.85940

[15] Halim M. H.: Truck tyre tread rubber: Compounding and abrasion resistance. $\mathrm{PhD}$ thesis, Loughborough University (1990).

[16] Lee M. P., Moet A.: Analysis of fatigue crack propagation in NR/BR rubber blend. Rubber Chemistry and Technology, 66, 304-316 (1993). https://doi.org/10.5254/1.3538314

[17] Kim H., Hamed G. R.: On the reason that passenger tire sidewalls are based on blends of natural rubber and cispolybutadiene. Rubber Chemistry and Technology, 73, 743-752 (2000).

https://doi.org/10.5254/1.3547618

[18] Ghosh P., Mukhopadhyay R., Kankroli R., Stoček R.: Durability prediction of NR/BR and NR/SBR blend tread compounds using tear fatigue analyser. Kautschuk Gummi Kunststoffe, 69, 53-55 (2016).

[19] Saiwari S.: Post-consumer tires back into new tires: Devulcanization and re-utilization of passenger car tires. $\mathrm{PhD}$ thesis, University of Twente (2013).

https://doi.org/10.3990/1.9789036535410

[20] Ayyer R., Rosenmayer T., Schreiber W., Colton J.: Effects of micronized rubber powders on structure and properties of polypropylene composites. Waste and Biomass Valorization, 4, 65-71 (2013).

https://doi.org/10.1007/s12649-012-9166-y

[21] Gibala D., Hamed G. R.: Cure and mechanical behavior of rubber compounds containing ground vulcanizates. Part I - Cure behavior. Rubber Chemistry and Technology, 67, 636-648 (1994).

https://doi.org/10.5254/1.3538699

[22] Fei Z., Long C., Qingyan P., Shugao Z.: Influence of carbon black on crosslink density of natural rubber. Journal of Macromolecular Science Part B: Physics, 51, 1208-1217 (2012). https://doi.org/10.1080/00222348.2012.664494

[23] Phadke A. A., De S. K.: Use of cryoground reclaimed rubber in natural rubber. Conservation and Recycling, 9, 271-280 (1986). https://doi.org/10.1016/0361-3658(86)90017-2
[24] Buist J. M., Kennedy R. L.: Tear resistance. More accurate results using I.C.I. tear cutter. Rubber Chemistry and Technology, 20, 281-287 (1947).

https://doi.org/10.5254/1.3546869

[25] Gibala D., Thomas D., Hamed G. R.: Cure and mechanical behavior of rubber compounds containing ground vulcanizates: Part III. - Tensile and tear strength. Rubber Chemistry and Technology, 72, 357-360 (1999). https://doi.org/10.5254/1.3538807

[26] Pittolo M., Burford R. P.: The mechanical properties of rubber compounds containing soft fillers. Journal of Materials Science, 19, 3330-3336 (1984).

https://doi.org/10.1007/BF00549822

[27] Clarke J., Clarke B., Freakley P. K.: Relationships between mixing method, microstructure and strength of NR:BR blends. Rubber Chemistry and Technology, 74, $1-15$ (2001). https://doi.org/10.5254/1.3547636

[28] Hamed G. R.: Molecular aspects of the fatigue and fracture of rubber. Rubber Chemistry and Technology, 67, 529-536 (1994). https://doi.org/10.5254/1.3538689

[29] Reincke K., Grellmann W., Lach R., Heinrich G.: Toughness optimization of SBR elastomers - Use of fracture mechanics methods for characterization. Macromolecular Materials and Engineering, 288, 181-189 (2003). https://doi.org/10.1002/mame.200390011

[30] Hamed G. R., Kim H. J., Gent A. N.: Cut growth in vulcanizates of natural rubber, cis-polybutadiene, and a $50 / 50$ blend during single and repeated extension. Rubber Chemistry and Technology, 69, 807-818 (1996). https://doi.org/10.5254/1.3538404

[31] Mathew N. M., De S. K.: Scanning electron microscopy studies in abrasion of NR/BR blends under different test conditions. Journal of Materials Science, 18, 515-524 (1983).

https://doi.org/10.1007/BF00560641

[32] Arayapranee W.: Rubber abrasion resistance. in 'Abrasion resistance of materials' (ed.: Adamiak M.) InTech, Rijeka, 147-166 (2012). https://doi.org/10.5772/30556

[33] Holland G. W., Hu B., Holland S.: Surface area measurement of ground rubber using the B.E.T. surface area analyzer. Rubber World, 210, 29-33 (1994).

[34] Hong C. K., Kim H., Ryu C., Nah C., Huh Y-i., Kaang S.: Effects of particle size and structure of carbon blacks on the abrasion of filled elastomer compounds. Journal of Materials Science, 42, 8391-8399 (2007). https://doi.org/10.1007/s10853-007-1795-3 